\title{
Conducting online crime and safety surveys with British farmers by Smith, K.
}

Copyright, publisher and additional information: This is the authors' accepted manuscript. The published version is available via Sage.

Please refer to any applicable terms of use of the publisher

DOI link to the version of record on the publisher's site University 
Abstract

4

Rural crime continues to be an under-represented area of academia. As a

5 result, much of the methodological guidance tends to stem from health or rural

6 development research, providing general guidance, but lacking the specific considerations of conducting crime and safety research in a rural environment. However the impact of COVID-19 has led to a wider consideration of online surveys, particularly in rural communities. This paper provides guidance on conducting online crime and safety surveys with the farming community based on extensive experience of the author in the field of rural criminology. Methodological considerations will be addressed that distinguish rural online crime and safety surveying from its urban counterpart, and the advantages and disadvantages of this methodology will be discussed. The aim being to guide the rural criminological researcher in the use of online surveys to obtain key data from the farming community to support and extend their research.

Key Words:

Rural; Surveys; Research Methods; Criminology

\section{Introduction}

Online surveys are structured questionnaires that are set up, disseminated, and completed by participants over the internet (Usability.gov, undated), and provide a simple, low cost, uncomplicated (although increasingly sophisticated) method of gathering primary survey data from a population without having to use telephone, 
postal, or face-to-face methods. Online surveys have been used for at least the last two decades as a data collection methodology for researchers across a range of subject areas, including education (Roberts \& Allen, 2015), marketing (llieva, et al. 2002), and health research (Geldsetzer, 2020). However, rural online surveys, those online surveys focusing specifically on issues affecting rural areas and rural communities, often tend to be limited to research in rural health (Chen et al., 2019; Curran et al., 2006) and rural development (Pašakarnis et al., 2013; Perez y Perez \& Egea, 2019), particularly in the developing world (Ahmad et al., 2019; Warugaba et

al., 2016). There are few examples of the use of rural online surveys in academic research with British farmers. Some of these are crime-related (Smith, 2017, 2020), while most are not (Easton et al., 2018; May et al. 2019). Many of the online surveys conducted with British farmers tend to be carried out by key stakeholders and representative organisations: Future Farmers Survey (NFU, 2020), Big Farmland Bird Count (GWCT, 2021), June Survey of Agriculture and Horticulture (Defra, 2020a).

Many aspects of conducting a Rural Online Crime Survey (ROCS) with farmers will reflect the general methodology used for any other population. However, there are extra considerations to be made when conducting a ROCS with farmers that would not be experienced in other areas of research. While some insights can be gleaned from online survey research in other areas, no methodological guidance currently considers what a rural criminological researcher must consider when planning to survey farmers. This paper will discuss the advantages and disadvantages of conducting a ROCS with the farming community of Britain, based on the authors' experiences, and aims to help the reader consider the research 
design and the adaptations required to ensure all key aspects are considered when planning to carry out a ROCS with farmers.

\section{Rural Online Surveys: A Brief History}

Historically, the pace of social science research methodology development has been somewhat staid (Hooley et al., 2012). However, since the development of the internet, and email and web-based surveys in the mid-1990s, social science research methodologies have come a long way (Fricker \& Schonlau, 2012). As use of the internet exploded in the early 2000's, researchers started to explore ways in which this technology could aide in their own research.

In the late 1990s, the use of online surveys was mainly driven by businesses looking to get evaluation on their services (Kehoe \& Pitkow, 1996), and so were limited in nature. However, some researchers were discovering the potential of the internet as a methodological tool at around the same time (O'Lear, 1996; Smith, 1997) noting the ability to reach a wider audience at a fraction of the cost and time. Despite issues around the detrimental effect online surveys have on response rates compared to traditional paper surveys being discussed in the mid-1990s (Schuldt \& Totten, 1994), the online survey nevertheless grew in popularity across a wide range of researchers within social science. Evans \& Mathur (2018) discussed at length the rapid growth of online survey research, including the development of ever more sophisticated online survey software and the popularity of online surveys, since their previous paper (Evans \& Mathur, 2005).

For the rural researcher, it is often the case that the benefits outweigh the pitfalls of going online survey research. It seems to have taken the rural research community a little time to realise that this methodology as beneficial in reaching 
sparse and remote communities without the need for extensive travel and administration (Wright, 2005; Geldsetzer, 2020). As the methodology has developed, so too have the ethics around the method, and the technology available to administer online surveys. Despite this, it is only in recent times that online surveys have been used to explore issues around rural crime. In the UK currently, there have been very few examples of academic research employing this methodology and only, seemingly, within the last 5 years (Smith, 2017, 2020; Morris, et al. 2017; Morris \& Norris, 2020). Rural stakeholders continue to dominate the use of online surveys to explore rural crime (Farmers Weekly, 2019; National Rural Crime Network, 2018; NFU Cymru, 2021; NFU Mutual, 2020).

\section{Methodological Pros and Cons}

When making decisions on how to conduct your data collection within the farming community, regardless of your location, you should first consider the methodological implications for each method under scrutiny and establish which will allow you to do your research in the most effective way possible. Much methodological discussion on online surveys is based on the 'typical' (Levy et al., 2017) approach to engaging participants, which roughly translated means the 'urban approach. Your survey may be a stand-alone piece of quantitative research, or it may be a part of a much wider mixed methods approach working from a pragmatic philosophical standpoint. However your crime survey fits into your research methodology, the mode of delivery should be carefully considered. Each option, whether face-to-face, mail, telephone, or online will have advantages and disadvantages that should be considered. Here, the pros and cons of online surveys per se, which are equally relevant to a ROCS, are briefly discussed before more 
detailed considerations of the implications when working with farmers are considered in the following sections.

Smyth et al. (2010) argued that online surveys are now the least expensive survey method available, and have the potential to also increase the speed in which data is gathered. The former is certainly true, online surveys mean only one researcher is required to gather the data, rather than relying on a team of research assistants, and factoring in travel, telephone or postage costs is no longer required. However, the literature seems to be split on the issue of online surveys being quicker to administer. Fricker \& Schonlau (2012) argued that there is little or no evidence to support the assertion that online surveys can reduce the time needed to field a survey. While this may be true, this aspect is controlled by the researcher. It is the researcher who decides how long a survey will be open for, whether three weeks or three months. What does seem to be clear, is the time a researcher saves in other aspects by using online surveys over other methods. The questionnaire itself is often easier to draft given that most online survey software options have various templates for question styles already programmed (Wright, 2005), and so saves time in the formatting of the questions.

However, the main time-saving aspect of online surveys can be seen when the survey is live and after the survey is closed. Once the survey is made live, the researcher can send out the details to their network and contacts as required, and apart from the regular reminders to potential participants via social media for example, the researcher is free to get on with other work they might not have been able to do using another method (llieva et al., 2002). Whereas you might be tied up with telephone calls, emails or travel using other means of surveying, the online survey allows you to work on other tasks while your survey is live (Andrews et al., 
2003). In addition, and more notably, the time savings seen once the survey has closed are evident in respect of the data input, coding, and cleaning. If using other methods, a substantial amount of time would be required by you to establish a coding system for each question, input the responses into a database, and then clean the data before any analysis can take place (llieva et al., 2002). With online surveys, coding is set when creating the questions, data can be exported directly from the survey into a database, and is likely to require minimal cleaning in preparation for analysis. Some survey software may offer an option to export survey results directly into analysis software, making this process even easier for you. In addition, the potential for errors in data inputting is reduced to almost zero by using online survey software.

Most relevant for you as you undertake crime and safety research with the farming community, is the flexibility that online surveys offer in terms of their global reach. Online surveys, unlike almost all other survey methods, are not restricted by geography (Wright, 2005). The use of online surveys with the farming community means you can reach farmers that may live and work in very isolated locations, that if driving may take many hours, if not days, to reach. It also means that you have the opportunity to conduct crime and safety research with farmers internationally, and establish a global comparative which may add a further, unexpected, dimension to your research. The advancement of online survey methods over the last two decades has opened up the world to researchers who would otherwise not have the financial ability to conduct research to understand these communities.

As discussed, the development of online survey software has come a long way since the turn of the $21^{\text {st }}$ century when this method was still in its infancy, and any online survey might incur huge costs for coding (Fricker \& Schonau, 2012). The 
arrival of online survey providers such as SurveyMonkey, Jisc Online Surveys, and

SmartSurvey, has meant that anyone can create an online survey. While some survey providers are free and some require subscriptions, they all make the process of developing an online survey much easier. Using online survey software gives you increased flexibility in the development and creation of your questionnaire. It allows you the freedom to choose the design process that suits you best. If you are comfortable with the software, and confident with the questions you want to ask, you can create your questionnaire directly online. As a researcher, I tend to have a plan of the questions before starting to create the online questionnaire. By doing this, it will help you to set up the questionnaire online quickly and easily, as you will already know what questions you want to ask, how you want the responses to work (single option, multiple options, etc.), and what order you want to ask those questions. This also allows you to think about the content of your landing page, to inform the potential participant of the key information about the research.

Additionally, your final page where you should include a thank you for your participants, and any contact details for organisations your participant can contact for help or support in relation to your piece of research. For example, in my last online survey, the topic of research was around mental health impacts of agricultural crime. On my last page of the survey, I added contact details for the NHS, and some mental health charities both general and farming specific.

Once you have your question list, you can start building your online questionnaire. Most online packages are fairly intuitive and offer various question types, and the option to set some questions as mandatory if they are essential to your research. There are a range of options on question types, some of which include single answer 'radio buttons', multiple choice, drop down lists, and Likert- 
type scales. In addition, there is the option for open questions where you want to gather additional information (Online Surveys, undated). You will also find advanced options such as question routing logic, that will enable you to direct your participant to the next relevant question by showing or hiding questions based on their previous response (Nayak \& Narayan, 2019).

Of course, regardless of the positives that online surveys can provide for the rural crime and safety researcher, there will always be disadvantages to be considered as part of your methodology and justification of choices. Online surveys, while time- and money-saving, present the rural crime researcher with issues that must be addressed.

Some research has raised the questions about how ethical issues such as consent, risk, privacy, anonymity, and confidentiality can be addressed using online surveys (Buchanan et al., 2009). However, it is arguable that this can be addressed easily in the design of the questionnaire. Having a distinct front page to the questionnaire that introduces the research, who you are and why you are doing the research, and your contact details, along with a brief but appropriate and effective informed consent statement should address any questions around ethical compliance that may have been raised. This is something that is easy to do with the online survey software now available. By setting out the appropriate informed consent protocol on the front page allows you to state that by clicking 'continue' the participant is providing their consent to be part of the research.

Such issues should be addressed during the initial ethical approval stage as required for any piece of research, and it is essential that ethical approval of the data gathering is obtained prior to you launching any questionnaires. This will address issues around the responsible and ethical conduct of the research, including 
informed consent, participant confidentiality and anonymity, and importantly will ensure that the participants are protected from risk or harm when taking part in the research (Gelling, 2016). You should be able to provide an indication of the questions you intend to ask, along with a draft of your informed consent statement as part of your ethics application so the appropriate committee can fully review your proposed research. Without ethical approval, the validity of the entire research can be brought into question, and it may mean that you are unable to receive grant funding and the potential that you will not be able to publish your findings in a peerreviewed journal (Newson \& Lipworth, 2015).

Increasingly rural criminological researchers are using online surveys as part of their research, and as such have to accept legitimate concerns of potential participants that would not otherwise be raised. Such concerns revolve predominantly around worries about cybercrime and data protection. This may be a question you are asked as a researcher by your potential participant. The key thing here is to check the data protection policy for your online survey provider. However, due to legislative compliance duties, almost all legitimate online survey providers should set out clearly how they protect and handle the data provided by participants. Any survey response should be collected over encrypted connections, and data should be securely stored with the right of the participant to request any personal data be deleted. You should consider including a data protection statement, or at least a link to a data protection statement, as part of your front-page information. This will enable your participant to be secure in the knowledge of how their personal data, if any is collected, will be handled. Of course, it is possible to conduct a survey without obtaining any personal data. This approach would enable you to be 
compliant with data protection legislation, and also to protect your participants' anonymity.

Of course, anonymity is easily maintained when conducting a ROCS if you do not ask for any identifiable data. For example, an urban online crime survey may be able to request location data at a postcode level as it is likely that there will be numerous properties within one postcode area. To do the same with a ROCS is problematic, as some rural areas are so sparsely populated, by using a postcode as a location identifier risks identifying a participant because there may only be a small number of properties within a postcode area, and potentially only one farm. A rural criminological researcher would be better working at a county or regional level for location data to avoid such issues and protect participant anonymity.

One of the downsides of online surveys is the inability to control who is completing the survey, and more importantly how many times one person can complete it. While Nayak \& Narayan (2019) argue that completion of the survey can be limited by enabling cookies, in reality it is often much harder to limit multiple completions of a survey, despite guidance on this issue on many online survey provider websites (SurveyMonkey, undated). As more people have increasing access to multiple devices, enabling cookies will only block the survey from being repeated from the device it was originally completed on. Furthermore, if cookies are cleared off a single device, this will allow the survey to be completed again by the same person from the same device.

As will be seen below, it is essential to ensure that your questionnaire is not too long in order to maximise the number of completions. If you have too long a front page, this may also deter potential participants from completing the questions. In addition, online surveys present a range of issues around sampling methods, and 
the biases that should be considered and addressed as discussed further in the next section. This is particularly relevant when considering research with farming communities.

\section{Rural Online Crime Surveys: Methodological Considerations}

In addition to the methodological issues already considered, there are a number of reliability factors that need to be addressed when conducting crime surveys with farmers. Issues that are less likely to be encountered if surveying urban residents, include whether age of participants, language, and the challenges of cognitive dissonance (Festinger, 1962) and rural masculinity (Brandth \& Haugen, 2015) may have a bearing on accessibility and likelihood of participation. While age and language may also have an effect on the accessibility and participation of urban residents, as will be seen in the remainder of this paper, for the rural crime researcher these factors are coupled with the desire of many farmers to protect the image of the rural idyll (Mingay, 1989), and the persistence of the idea that farmers should be strong and silent (Connell, 1995). Any combination of these factors, and others, can have a bearing on the reliability and repeatability of your research.

\section{Think about your Questions}

As a ROCS can often address complex or emotive issues it is essential for the rural criminological researcher to be aware of these factors and how they can influence the way in which a participant might answer a question. Poorly worded or complex questions, and even the order of questions - order effects bias (Serenko \& Bontis, 2013), can influence how people respond. For example, poorly worded or complex questions may mean that the participant is not entirely clear on how they 
should answer. In addition, questions that may be leading, or asks whether the participant agrees with a statement could introduce acquiescence bias whereby the participant responds with a positive answer rather than the answer that best reflects their attitude (Costello \& Roodenburg, 2015). These issues can generally be overcome by ensuring that you think carefully about the wording and order of your questions. Try to avoid ranking questions, and try to use Likert statements with a satisfaction scale rather than an agreement scale. Also, if using Likert statements, where possible use some negatively worded statements so that your participant has to consider the appropriate response to each statement rather than simply selecting that which seems most socially acceptable.

The essential step here, is to get advice on your survey questions if you are not sure, and to pilot your questionnaire with friends or colleagues before you publish it, as discussed in more detail with the internal validity considerations. This will help you identify any issues that you may have overlooked when writing your questionnaire and allow you the opportunity to fix them to address potential participant biases driven by the questions.

It is important, not only to think about the wording and the order of your questions, but also how many questions you wish to ask. It is important to only ask as many questions as you need to obtain the data needed to answer your overarching research question. If you ask too much, you run the risk of your participant losing interest half way through your questionnaire, leaving it, and not returning to complete it. Attention research suggests that your survey should take no longer than 10-15 minutes to complete (Bradbury, 2016). In addition, in accordance with general ethical procedures, you should only be gathering pertinent, relevant information as required for your specific research (Market Research Society, 2019). 
As farmers have so many things they need to do and you are not there in person to explain the importance of the ROCS, it is essential to ensure that the key point of the ROCS is clear at the outset, and the benefit this will have to the participant, but also their community, is set out at the earliest opportunity. The landing page for your ROCS should set this out in the first line or two, and this message should be impactful to engage your potential participant. These factors are essential to consider to ensure your methodological approach is sound, and that the research is repeatable. While online survey provision can ensure that surveys can easily be repeated, if the questions you ask are problematic in any way, or if the questionnaire is too long, it makes it less likely that another researcher could repeat your work.

\section{Sampling Considerations and External Validity}

The general process of creating a questionnaire for online use is fairly standard. The researcher should consider the key research question to be addressed, and devise appropriate questions to obtain the right data to begin to address that question. However, for the rural criminological researcher, there are numerous additional issues around the reliability and validity of the questionnaire and the survey process that need to be considered in addition when working with farmers. While there is extant literature that makes use of an online research methodology with farming communities, very often little attention is paid to the minutiae of methodological considerations that must be addressed when working in rural communities. This can make it hard to understand the additional decisionmaking that should be undertaken, especially for rural criminological researchers who are working with farmers for the first time. As such, this section discusses some 
324 of the issues around reliability and validity of a ROCS, and whilst not exhaustive, will

enable appropriate attention to be paid to these additional aspects to ensure successful data gathering.

Once you have obtained ethical approval for your research, and you are satisfied that a ROCS is the right method for data collection, you then need to consider your target population. Rural communities, and farmers in particular, should arguably be thought of as hard-to-reach communities; they are both socially and geographically isolated, and are a group that is historically excluded from social research (Ellard-Gray, et al., 2015). This may be partly due to farming communities being overlooked by researchers and policy-makers as key informants in the past, but also partly due to a general unwillingness of farming communities to trust those who are not part of their community, and not wanting to stand out from the crowd by talking to a researcher who may be seen as an 'intruder' in the close-knit community (Bulmer, 1983). While the openness of farming communities in Britain is improving, the persistence of traditional cultures, attitudes, and rural masculinity in some communities continue to make things hard for rural criminological researchers, and makes the challenge of helping them understand that your rural crime and safety research is relevant to them, but also their community, much harder (Pelletier, et al., 2020).

While not exclusively the case, many online surveys conducted with urban populations in fields such as marketing and health will have the luxury of selecting a random sample based on customer databases to directly contact and request participation in the online survey. This further allows for post-hoc analysis on responses, partial responses, and non-responses to establish whether any biases may have been introduced (Evans \& Mathur, 2005). However, Evans \& Mathur (ibid) 
based their methodological guidance on very much urban-focused research, and it is unlikely that a rural criminological researcher will have access to a database of farmers' details. While these do exist, they are only accessible by members of that particular organisation such as government departments and agencies, and farmer representative organisations such as the National Farmers Union (NFU) in Britain. In addition, as a result of Data Protection laws, even the organisations that hold these details can only contact those farmers for reasons previously agreed which are unlikely to include third party research.

By focusing your rural crime research on farmers in Britain (or any other country), this immediately makes your sampling frame much smaller, which therefore means that your intended sample will not be as large as if you were targeting the whole UK population and is more open to sampling bias (Lavrakas, 2008) such as selection bias (Agresti, 2018). While you should find identifying your target sample fairly straightforward, for example British farmers who have been a victim of hare coursing, by framing your sample in this way may introduce selection bias insofar as there may be a tendency for the participants who complete your ROCS to be selfselecting (Heckman, 1990). This will generally mean that someone is more likely to complete your ROCS if they have been affected by the issue at hand, in this case hare coursing. This could be a positive thing if you are only looking for experiences of those farmers who have been a victim of hare coursing as it will provide direct feedback on actual experiences. However, as a rural criminological researcher you should consider whether it is relevant to get responses from those who have not been directly affected by this issue to allow an exploration of any differences seen in the data that may relate directly to the overarching research question. Such a situation would lead to self-selection bias where your sample may no longer 
represent the target population (Khazaal et al., 2014) with some researchers arguing that self-selection through online surveys may lead to unreliable survey outcomes (Bethlehem, 2010). In a bid to address the issues around self-selection as much as is possible, it may be wise to try and aim your ROCS at all members of the population, in this example British farmers, and then through the use of question routing logic enable participants to answer only those questions relevant to them based on their previous responses. This will then allow you to obtain a wider field of participants than just those British farmers who have been a victim of hare coursing. This was the approach adopted by Smith (2017) where data from farmers who had been a victim of farm crime was obtained, as well as responses from those farmers who had not victims.

You may further choose to focus your rural crime research on a particular section of the British farming community: farming sector, region, or farm size for example. Whichever way you choose your sample, by opting for a ROCS, the likelihood is that your sampling technique will be non-random, providing nonparametric data for your analysis as it is likely to violate normal distribution assumptions (Pallant, 2013). This can have implications on the potential external validity of the ROCS, insomuch as the possibility that any analysis will provide results that can be reported as representative of the population will be difficult to justify. While non-random sampling cannot traditionally produce representative findings, you can justify your approach by treating your results as indicative of the response one might obtain if the whole population took part in the research. However, research conducted by Heen, et al. (2014) comparing three online survey methods, found that the demographics of the samples fell within a $10 \%$ range of the corresponding values in the US population, and so it could be argued that issues 
around the representativeness and generalisability of data obtained through a ROCS

400

401

402

403

404

405

406

407

408

409

410

411

412

413

414

415

416

417

418

419

420

421

422

423

using non-random sampling methods may be overcome. It is wise to try and obtain demographic information from participants in a format that resembles an existing dataset for comparability, such as the demographic data obtained in the Defra (2020b) 'Agriculture in the United Kingdom' statistics updated annually.

\section{Hard-to-Reach Farmers and External Validity}

Another aspect of sampling bias that may be more prevalent in rural crime research and can affect the external validity of your research, is that of non-response bias (Berg, 2010). This occurs when participants refuse to take part, or are unable to take part, and can raise validity issues as we do not know whether those people who did not respond would have answered the questions in a different way to those who did respond. This makes it harder to establish that results obtained can be generalised to all British farmers. This issue is compounded by the fact that, with non-random sampling of the farming community, there is no clear sampling frame (a list of all subjects in the population) from which to choose the sample, and so it is not clear how many people have seen the request for participants, thus an inability to accurately identify a response rate. Despite some research suggesting that the type and quality of responses using online surveys are comparable to paper-based surveys (Gordon \& McNew, 2008), the nearest one might get, is to report the completion rate of the survey, however this depends upon the survey software used and whether this data is captured. Smith (2020) adopted this approach to provide an estimated completion rate of $5.1 \%$ on the online survey based on how many people viewed the landing page, compared to the number of completed surveys received. Even as an indicative completion rate, it is clear from this how difficult it can be to 
encourage participation from the farming community at times. This reluctance persists despite the anonymity of a ROCS, possibly as a result of the historic lack of involvement of rural communities in academic crime and safety research (Smith, 2018).

Where discussion arises around people not being able to take part in a ROCS, this is particularly pertinent with farming communities. As noted above, such communities should be considered as hard-to-reach due to their social and geographic isolation. However, when considering a ROCS, one should consider the technological isolation of these communities and whether the definition of hard-toreach should indeed be extended. From the perspective of conducting a ROCS, and access to decent broadband services.

In Britain, the median age of farmers in 2019 was 60 (Defra, 2020b). This is compared to the median age of 47 across the general working age population (aged $16+)$ at the same time (ONS, 2020). It is arguable that, despite having to submit various productivity and other data via online surveys, farmers in Britain are less likely to be regular users of the internet, in particular social media. This may mean they are less likely to become aware of a ROCS, particularly where the promulgation of such surveys is conducted solely online through social media, or online discussion forums. In addition, you should bear in mind that rural areas historically have more issues in rural broadband connectivity than their urban counterparts. In 2019 , up to $35 \%$ of rural premises in the UK were unable to access a decent broadband service compared to just $1 \%$ of premises in an urban area (Rural Broadband Statistics, 2019). These factors together can lead to issues of non-response, and potentially skewed data towards younger age groups and those who live in less remote areas. 
Such issues could potentially be addressed by ensuring that your ROCS is

450

451

452

453

454

455

456

457

458

459

460

461

462

463

464

465

466

467

468

469

470

471

472 promulgated using methods other than social media or online groups. Make use of local and national farming organisations, rural policing teams, farming charities, farming press, attending local events, and your own networks to send out information about your ROCS. Many of these organisations will be happy to help send out information about your research and encourage farmers to take part. If your research focuses on a particular crime and safety topic, make use of organisations that work within that area and who have contact with the farming community. Also, think about rural service providers, health care providers, veterinarians, livestock markets, anywhere farmers may visit. In addition, wherever possible, try and ensure that your ROCS is compatible with a variety of devices such as tablets and mobile phones. This may increase the chance of survey completion given that some of these devices may not be reliant on broadband connections for internet access. However, you must consider that not all farmers will have smartphones, and even some that do have smartphones may not have a data bundle as they may only use it to make calls or send texts. Keep sharing the details of your ROCS, even if this is only possible through social media. You will be hugely reliant on a snowball sampling, word-ofmouth approach with your methodology, so the more you keep the research in someone's social media feed, the more likely they will be to complete the ROCS, and pass on details to friends, family, and colleagues. All of this will help you to get as many responses as possible from farmers across all areas and increase the generalisability of your findings, thus increasing the external validity of your research. 
When designing your ROCS, you will have a huge range of factors to consider relating to reliability and external validity of the subsequent data sets as discussed above and whether the outcome of any analysis is consistent if the research were to be repeated, and such findings are generalisable to the wider population (i.e. British farmers). In addition to this, it is essential to take steps to ensure the internal validity of the ROCS is assessed. This will ensure you can justify that the data gathering instrument you have chosen to use is measuring what you intend it to measure (Kelley, 1927). In other words, the questions you are asking will provide the data needed to answer your overarching research question. While the issues relating to reliability (repeatability) and external validity (generalisability) have been discussed above in relation to the problems around identifying a clear sampling frame and controlled and assessed. eliminating biases, ensuring internal validity of your ROCS is something more easily

As online surveys offer the researcher the option of undertaking both crosssectional research and longitudinal research (Nayak \& Narayan, 2019), it is essential that appropriate evaluation of the questions are undertaken prior to the ROCS going live. This can be done by a small, simple pilot of the questionnaire. Once your ROCS questionnaire is finalised, and you have set up the questions in your online survey software, you can deliver this to a small number of colleagues to run as a pilot. As discussed above in relation to your questions, it will also allow you to ensure that the results are what you would expect for each question. By undertaking a pilot of the ROCS, it will ensure that the questions are being interpreted correctly by the pilot participants, and that they are able to provide appropriate responses which make sense in the context of the rural crime research. If you find that a question raises queries or pilot participants are unclear on the meaning, this allows you the 
opportunity to discuss this with your pilot participants and understand what the issue might be. You can then consider rewording the question, or removing the question altogether. This process will allow you to test your questions, but also the technology involved with the running of the ROCS, especially where you have any question routing logic set up, to ensure it all works, and should be seen as an essential stage in tour rural crime research project (Hassan et al., 2006). statistical software for analysis, if you have included any Likert-type questions in your survey, an additional step that is useful for the rural crime researcher to ensure internal validity of the results, is to run an analysis to establish the reliability level of the statistical analysis that would follow. This can be done using a Cronbach's Alpha analysis (Smith, 2018). By undertaking this analysis, it will allow you to indicate how closely related a group of items are, and although it is considered a measure of reliability of the scale used and not internal validity per se, it is argued that

Cronbach's Alpha can demonstrate that the construct of the scales used are fit for purpose (Taber, 2018). In other words, the Likert-type questions show construct validity (Lin et al., 2015).

\section{Rural Online Crime Surveys: Pros and Cons Overview}

A number of considerations have been set out in this paper relating to the pros and cons of ROCS for the rural criminological researcher. As an overview, this information is shown in Table 1 below.

\begin{tabular}{|l|l|}
\hline \multicolumn{1}{|c|}{ Advantages } & \multicolumn{1}{c|}{ Disadvantages } \\
\hline Cheaper to administer & $\begin{array}{l}\text { Higher possibility of biased data, low } \\
\text { response rates }\end{array}$ \\
\hline $\begin{array}{l}\text { Easy access to a global reach for target } \\
\text { population }\end{array}$ & $\begin{array}{l}\text { Harder to keep participants engaged for } \\
\text { more than 10 minutes }\end{array}$ \\
\hline
\end{tabular}




\begin{tabular}{|c|c|}
\hline $\begin{array}{l}\text { Plenty of good quality online survey } \\
\text { software, e.g. Onlinesurveys.ac.uk, } \\
\text { Survey Monkey }\end{array}$ & Harder to avoid repeated questions \\
\hline $\begin{array}{l}\text { Easy to promulgate to farming } \\
\text { community through social media, } \\
\text { stakeholders }\end{array}$ & $\begin{array}{l}\text { Harder to control who is answering, or if } \\
\text { submitting multiple responses }\end{array}$ \\
\hline $\begin{array}{l}\text { No cost-based or geographic } \\
\text { restrictions }\end{array}$ & $\begin{array}{l}\text { Harper to reach some farming } \\
\text { communities due to poor internet } \\
\text { access, connectivity, isolated } \\
\text { communities, 'hard-to-reach' } \\
\text { populations, older, less tech-savvy }\end{array}$ \\
\hline $\begin{array}{l}\text { Most software packages provide some } \\
\text { data automation, e.g. basic cross- } \\
\text { tabulation, coding }\end{array}$ & $\begin{array}{l}\text { Lack of random sampling leads to } \\
\text { problems with representativeness and } \\
\text { statistical confidence and margin of } \\
\text { error }\end{array}$ \\
\hline $\begin{array}{l}\text { Flexible design allows variety of } \\
\text { question types, question routing, etc. }\end{array}$ & Not all farmers are smartphone owners \\
\hline $\begin{array}{l}\text { May be the only way to access some } \\
\text { remote participants }\end{array}$ & $\begin{array}{l}\text { Worries among farming community of } \\
\text { cyber crime and data protection while } \\
\text { doing survey but also afterwards }\end{array}$ \\
\hline $\begin{array}{l}\text { Quicker to administer, clean data, } \\
\text { export data to statistical software }\end{array}$ & $\begin{array}{l}\text { Trust of farming community towards } \\
\text { researcher may affect response rate }\end{array}$ \\
\hline $\begin{array}{l}\text { Easier to ensure the completion of } \\
\text { mandatory questions, and identify } \\
\text { optional questions }\end{array}$ & $\begin{array}{l}\text { Easier for potential participants to } \\
\text { ignore }\end{array}$ \\
\hline $\begin{array}{l}\text { Flexibility to allow data gathering when } \\
\text { other methods may not be possible, e.g. } \\
\text { COVID-19, rather than research halting }\end{array}$ & $\begin{array}{l}\text { May still have skewed responses due to } \\
\text { respondent characteristics, e.g. male, } \\
\text { white, middle class }\end{array}$ \\
\hline $\begin{array}{l}\text { Enables longitudinal sectoral analysis to } \\
\text { track change over time }\end{array}$ & $\begin{array}{l}\text { Can only determine sample validity if } \\
\text { working with a customer database or } \\
\text { panel }\end{array}$ \\
\hline $\begin{array}{l}\text { No need to rely on local administrators } \\
\text { to deliver the survey }\end{array}$ & \\
\hline $\begin{array}{l}\text { Provides a truly anonymous method of } \\
\text { gathering data on complex or emotive } \\
\text { issues }\end{array}$ & \\
\hline $\begin{array}{l}\text { Potentially offers a way to gather } \\
\text { primary data that overcomes issues } \\
\text { around rural masculinity and resulting } \\
\text { stoicism }\end{array}$ & \\
\hline
\end{tabular}

Table 1: Overview of the advantages and disadvantages of ROCS 


\section{Rural Online Crime Surveys: An International Perspective}

Although this paper has focused on the use of ROCS in the UK to conduct rural criminological work, the question as to whether this methodology could be used internationally to reach remote communities currently remains largely unanswered. It is noted that the use of ROCS seems to currently be restricted to developed countries, most notably Australia (Harkness, 2017; Harkness \& Larkins, 2019). Interestingly however, even in Australian rural criminological research, it is sometimes necessary to supplement the ROCS with a hard copy of the survey to improve response rates (Harkness \& Larkins, 2019).

Rural crime research from the global south that is accessible to an international audience is less abundant than that from the global north partly due to a focus on a non-English speaking audience (e.g., Spanish, French, Portuguese, native languages). This imbalance is something that may be addressed by the move towards more Open Access publishing worldwide and FAIR Data Principles (Das, 2020), and fairer and more equitable collaborations between the global north and global south (Christian Aid, 2018). While online surveys are used in various research fields in the global south, the use of a ROCS as a data collection tool in rural criminological research is very much unexplored. It is possible that the use of a ROCS in areas such as South America, Africa, and Asia are heavily impacted by some of the issues explored in this paper, including poor connectivity, low levels of computer or smartphone ownership, or other socio-economic factors. As a result, the pathway towards widespread use of a ROCS in countries such as Kenya, Tanzania, and Ethiopia remains largely untravelled (Bunei \& Barasa, 2017; Neubacher et al., 2019; Zekiwos-Gichamo et al., 2019). 


\section{Conclusions}

Whether used as an exploratory tool or an explanatory tool in rural research, it is clear that online surveys assist the rural crime researcher in obtaining key quantitative data relating to a range of rural criminological topics from the farming community. Research conducted using this method is becoming much more widespread as the technology has developed, and rural broadband has improved. While the latter still needs improvement in the UK, online surveys allow rural crime researchers to obtain data on the experiences of the farming community who should be considered hard-to-reach, not just geographically and socially, but also technologically. Once initial hurdles including promulgation of the survey, and gaining the trust of the farming community are overcome, data can be obtained from farmers that may otherwise be unobtainable using traditional survey methods.

A ROCS will allow data to be obtained using a low-cost method that will support your ongoing crime and safety research either by identifying key themes to be explored further, or by providing data that supports earlier research findings. It is clear that there may be more things to consider around methodology, reliability and validity when conducting ROCS with farmers than would need to be considered if conducting a crime survey in an urban location. However, when considering the breadth of data that can be obtained from a ROCS with farmers, it is concluded that this method is an invaluable resource in the toolbox of the rural criminological researcher.

\section{References}

Agresti, A. (2018). Statistical Methods for the Social Sciences (5 $5^{\text {th }}$ Ed.) Harlow: Pearson. 
Ahmad, T., Alvi, A., Ittefaq, M. (2019). The Use of Social Media on Political Participation Among University Students: An Analysis of Survey Results from Rural Pakistan. SAGE Open, 9(3): 1-9. DOI: 10.1177/2158244019864484.

Andrews, D., Nonnecke, B., \& Preece, J. (2003). Electronic survey methodology: A case study in reaching hard-to-involve Internet users. International Journal of Human-Computer Interaction, 16(2): 185-210. DOI: 10.1207/S15327590IJHC1602_04.

Berg, N. (2010). Non-Response Bias. In K. Kempf-Leonard (Ed.) Encyclopedia of Social Measurement, Vol. 2. Pp 86-873. London: Academic Press.

Bethlehem, J. (2010). Selection bias in web surveys. International Statistical Review, 78(2): 161-188. DOI: 10.1111/j.1751-5823.2010.00112.x

Bradbury, N.A. (2016). Attention span during lectures: 8 seconds, 10 minutes, or more? Advances in Physiology Education, 40(4): 509-513. DOI: 10.1152/advan.00109.2016.

Brandth, B. \& Haugen, M. (2016). Rural Masculinity. In M. Shucksmith, \& D.L. Brown (Eds.) Routledge International Handbook of Rural Studies. London: Routledge. Pp. 412-424.

Buchanan, E.A., Hvizdak, E.E. (2009). Online Survey Tools: Ethical and Methodological Concerns of Human Research Ethics Committees. Journal of Empirical Research on Human Research Ethics, 4(2): 37-48. DOI: 10.1525/jer.2009.4.2.37.

Bulmer, M. (1983). Interviewing and Field Organization. In M. Bulmer \& D.P. Warwick (Eds.) Social Research in Developing Countries. New York: Wiley, pp. 207-219. 
596 Bunei, E. \& Barasa, F.O. (2017). Farm Crime Victimisation in Kenya: A Routine Activity Approach. International Journal of Rural Criminology, 3(2): 224-229.

Chen, X., Orom, H., Hay, J.L., Waters, E.A., Schofield, E., Li, Y., Kiviniemi, M.T. (2019). Differences in Rural and Urban Health Information Access and Use. Journal of Rural Health, 35(3): 405-417. DOI: 10.1111/jrh.12335. support fair and equitable research partnerships. Retrieved $28^{\text {th }}$ June 2021 from: https://www.christianaid.org.uk/sites/default/files/2018-09/Southernacademics-fair-equitable-partnerships-Sept-18_0.pdf.

Connell, R. (1995). Masculinities. Los Angeles, CA: University of California Press.

Costello, S. \& Roodenburg, J. (2015). Acquiescence Response Bias - Yeasaying and Higher Education. The Educational and Development Psychologist, 32(2): 105-119. DOI: 10.1017/edp.2015.11.

Curran, V.R., Fleet, L., Kirby, F. (2006). Factors influencing rural health care professionals' access to continuing professional education. Australian Journal of Rural Health, 14(2): 51-55. DOI: 10.1111/j.14401584.2006.00763.x.

Das, A.K. (2020). Open Research Data in the Global South: Issues and Anomalies in the Indian Context. In: Das K., Mishra B.S.P., Das M. (eds) The Digitalization Conundrum in India. India Studies in Business and Economics. Springer, Singapore. https://doi.org/10.1007/978-981-15-6907-4_14.

Defra (2020a). June survey of agriculture and horticulture. Retrieved $7^{\text {th }}$ April 2021 from: https://www.gov.uk/agricultural-survey. 
619 Defra (2020b). Agriculture in the United Kingdom 2019. Retrieved $21^{\text {st }}$ December

620

621

622

623

624

625

626

627

628

629

630

631

632

633

634

635

636

637

638

639

640

641

642 2020 from: https://www.gov.uk/government/statistics/agriculture-in-theunited-kingdom-2019.

Easton, S., Pinchbeck, G.L., Bartley, D.J., Hodgkinson, J.E., Matthews, J.B. (2018). A survey of experiences of UK cattle and sheep farmers with anthelmintic prescribers; Are the best practice principles being deployed at farm level? Preventive Veterinary Medicine, 155: 27-37. DOI:

10.1016/j.prevetmed.2018.04.009.

Ellard-Gray, A., Jeffery, N.K., Choubak, M., Crann, S.E. (2015). Finding the Hidden Participant: Solutions for Recruiting Hidden, Hard-to-Reach, and Vulnerable Populations. International Journal of Qualitative Methods, 14(5). DOI: 10.1177/1609406915621420.

Evans, J.R. \& Mathur, A. (2005). The value of online surveys. Internet Research, 15(2): 195-219. DOI: 10.1108/10662240510590360.

Evans, J.R. \& Mathur, A. (2018) The value of online surveys: a look back and a look ahead. Internet Research, 28(4): 854-887. DOI: 10.1108/IntR-03-2018-0089.

Farmers Weekly (2019) Exclusive survey: What farmers say about rural crime. Retrieved 10 $10^{\text {th }}$ June 2021 from: https://www.fwi.co.uk/news/crime/exclusivesurvey-what-farmers-say-about-rural-crime

Festinger, L. (1962). Cognitive Dissonance. Scientific American, 207(4): 93-106. Retrieved April 9, 2021, from http://www.jstor.org/stable/24936719.

Fricker, R.D. \& Schonlau, M. (2012). Advantages and Disadvantages of Internet Research Surveys: Evidence from the Literature. Field Methods 14(4): 347367. DOI: 1.1177/152582202237725. 
Geldsetzer, P. (2020). Use of Rapid Online Surveys to Assess People's Perceptions During Infectious Disease Outbreaks: A Cross-sectional Survey on COVID19. Journal of Medical Internet Research, 22(4): e18790. DOI: 10.2196/18790

Gelling, L. (2016). Applying for ethical approval for research: the main issues. Nursing Standard, 30(20): 40-44. DOI: 10.7788/ns.30.20.40.s46.

Gordon, J.S. \& McNew, R. (2008). Developing the Online Survey. Nursing Clinics of North America, 43(4): 605-619. DOI: 10.1016/j.cnur.2008.06.011.

GWCT. (2021). 2021 Big Farmland Bird Count. Retrieved 7th April 2021 from: https://www.bfbc.org.uk/.

Harkness, A. (2017). Crime Prevention on Farms: Experiences from Victoria, Australia. International Journal of Rural Criminology, 3(2): 131-156.

Harkness, A. \& Larkins, J. (2019). Farmer satisfaction with policing in rural Victoria, Australia. International Journal of Rural Criminology, 5(1): 47-68.

Hassan, Z.A., Schattner, P., Mazza, D. (2006). Doing A Pilot Study: Why Is It Essential? Malaysian Family Physician, 1(2-3): 70-73.

Heckman J.J. (1990). Selection Bias and Self-selection. In: J. Eatwell, M. Milgate, P. Newman (Eds) Econometrics. Palgrave Macmillan: London. Pp. 201-224. DOI: 10.1007/978-1-349-20570-7_29

Heen, M.S.J., Lieberman, J.D., Miethe, T.D. (2014). A Comparison of Different Online Sampling Approaches for Generating National Samples. Center for Crime and Justice Policy 1(9): 1-8. Retrieved on $8^{\text {th }}$ April 2021 from: https://www.unlv.edu/sites/default/files/page files/27/ComparisonDifferentOn lineSampling.pdf. 
Hooley, T., Marriott, J., Wellens, J. 2012. What is Online Research? Using the Internet for Social Science Research. London: Bloomsbury Academic.

llieva, J., Baron, S., Healey, N.M. (2002). Online surveys in marketing research: pros and cons. International Journal of Market Research, 44(3): 361-376. DOI: $10.1177 / 147078530204400303$.

Kehoe, C. \& Pitkow, J. (1996). Surveying the territory: GVU's five WWW user surveys. The World Wide Web Journal, 1(3): 77-84.

Kelley, T.L. (1927). Interpretation of Educational Measurements. New York: Macmillan.

Khazaal, Y., van Singer, M., Chatton, A., Achab, S., Zullino, D., Rothen, S., Khan, R., Billieux, J., Thorens, G. (2014). Does Self-Selection Affect Samples' Representativeness in Online Surveys? An Investigation in Online Video Game Research. Journal of Medical Internet Research, 16(7): e164. DOI: 10.2196/jmir.2759.

Lavrakas, P.J. (2008). Sampling Bias. Encyclopedia of Survey Research Methods (Vols. 1-0). Thousand Oaks, CA: Sage. DOI: 10.4135/9781412963947.

Levy, M., Holmes, C., Mendenhall, A., Grube, W. (2017). Engaging rural residents in patient-centered health care research. Patient Experience Journal, 4(1): 4653. DOI: $10.35680 / 2372-0247.1164$.

Lin, T.C., Liang, J.C., Tsai, C.C. (2015). Conceptions of memorizing and understanding in learning, and self-efficacy held by university biology majors. International Journal of Science Education, 37(3): 446-468. DOI: 10.1080/09500693.2014.992057. Market Research Society (2019). Code of Conduct. Retrieved on 08/04/2021 from https://www.mrs.org.uk/standards/code-of-conduct. 
692

693

694

695

696

697

698

699

700

701

702

703

704

705

706

707

708

709

710

711

712

713

714

May, D., Arancibia, S., Behrendt, K., Adams, J. (2019). Preventing young farmers from leaving the farm: Investigating the effectiveness of the young farmer payment using a behavioural approach. Land Use Policy, 82: 317-327. DOI: 10.1016/j.landusepol.2018.12.019.

Mingay, G.E. (1989). The Rural Idyll. London: Routledge.

Morris, W., Norris, G. (2020) Rural and Farm Crime in Dyfed-Powys: Second Report. Aberystwyth University.

Morris, W., Norris, G., Dowell, D. (2017). Final report to Dyfed-Powys Police: Farm and Rural Crime. Aberystwyth University.

National Rural Crime Network (2018). Living on the Edge: National Rural Crime Survey. Retrieved on $10^{\text {th }}$ June 2021 from: https://www.nationalruralcrimenetwork.net/research/internal/2018survey/

Nayak, M.S.D.P. \& Narayan, K.A. (2019). Strengths and Weakness of Online Surveys. IOSR Journal of Humanities and Social Science, 24(5): 31-38. DOI: 10.9790/0837-2405053138.

Neubacher, F., Faße, A., Bögelein, N., Grote, U. (2019). Victimization and Fear of Crime in Rural Tanzania. International Journal of Rural Criminology, 4(2): 173-192.

Newson, A.J. \& Lipworth, W. (2015). Why should ethics approval be required prior to publication of health promotion research? Heath Promotion Journal of Australia, 26: 170-175. DOI: 10.1071/HE5034.

NFU (2020). Future Farmers Survey. Retrieved on $7^{\text {th }}$ April 2021 from: https://nfuresearch.nfuonline.com/s.asp?k=158445768976. 
NFU Cymru (2021) NFU rural crime survey 2021: share your experience. Retrieved on $10^{\text {th }}$ June 2021 from: https://www.nfu-cymru.org.uk/cross-sector/ruralcrime/rural-crime-news/nfu-rural-crime-survey-2021-share-your-experience/

NFU Mutual (2020). A Challenging Time for the Countryside: Rural Crime Report 2020. Retrieved on $10^{\text {th }}$ June 2021 from: https://www.nfumutual.co.uk/farming/ruralcrime/

O'Lear, S.R.M. (1996). Using Electronic Mail (E-mail) Surveys for Geographic Research: Lessons from a survey of Russian environmentalists. The Professional Geographer, 48(2): 213-22. DOI: 10.1111/j.00330124.1996.00209.x.

OnlineSurveys (undated). Question types. Retrieved on $9^{\text {th }}$ April 2021 from: https://www.onlinesurveys.ac.uk/help-support/question-types/

ONS (2020). Population estimates for the UK, England and Wales, Scotland and Northern Ireland: mid-2019. Retrieved on $8^{\text {th }}$ April 2021 from: https://www.ons.gov.uk/peoplepopulationandcommunity/populationandmigrat ion/populationestimates/bulletins/annualmidyearpopulationestimates/mid201 9estimates.

Pallant, J. (2013). SPSS survival manual: A step by step guide to data analysis using IBM SPSS (4th ed.). Crows Nest, NSW: Allen \& Unwin.

Pašakarnis, G., Morley, D., Malienè, V. (2013). Rural development and challenges establishing sustainable land use in Eastern European countries. Land Use Policy, 30(1): 703-710. DOI: 10.1016/j.landusepol.2012.05.011.

Pelletier, C.A., Pousette, A., Ward, K., Fox, G. (2020). Exploring the perspectives of community members as research partners in rural and remote areas. 
Research Involevement and Engagement, 6: 3. DOI: 10.1186/s40900-0200179-6.

Perez y Perez, L., Egea, P. (2019). About Intentions to Donate for Sustainable Rural Development: An Exploratory Study. Sustainability, 11(3): 765. DOI: $10.3390 /$ su11030765.

Roberts, L.D., Allen, P.J. (2015). Exploring Ethical Issues Associated with Using Online Surveys in Educational Research. Educational Research and Evaluation, 21(2): 95-108. DOI: 10.1080/13803611.2015.1024421.

Rural Broadband Statistics. (2019). Retrieved 28th March 2021 from

\section{https://www.gov.uk/government/statistics/rural-broadband}

Schuldt, B.A. \& Totten, J.W. (1994). Electronic mail vs. mail survey response rates. Marketing Research, 6(1): 36-9.

Serenko, A., Bontis, N. (2013). First in, best dressed: The presence of order-effect bias in journal ranking surveys. Journal of Informetrics, 7(1): 138-144. DOI: 10.1016/j.joi.2012.10.005.

Smith, C. (1997). Casting the Net: surveying an internet population. Journal of Computer-Mediated Communication, 3(1): JCMC316. DOI: 10.1111/j.10836101.1997.tb00064.x.

Smith, K. (2017). Farm crime in England and Wales: a preliminary scoping study examining farmer attitudes. International Journal of Rural Criminology, 3 (2). pp. 191-223. DOI: 10.18061/1811/81047.

Smith, K. (2018). Behavioural Science and Farm Crime Prevention Decision Making: understanding the behavioural culture of farmers in England and Wales. Retrieved $9^{\text {th }}$ April 2021 from: https://hau.repository.guildhe.ac.uk/id/eprint/17339/. 
Smith, K. (2020). Desolation in the Countryside: How agricultural crime impacts the mental health of British farmers. Journal of Rural Studies, 80: 522-531. DOI: 10.1016/j.jrurstud.2020.10.037.

Smyth, J.D., Dillman, D.A., Christian, L.M., O’Neill, A.C. (2010). Using the Internet to Survey Small Towns and Communities: Limitations and Possibilities in the Early $21^{\text {st }}$ Century. American Behavioral Scientist, 53(9): 423-1448. DOI: 10.1177/0002764210361695.SurveyMonkey (undated). Allowing Multiple Responses. Retrieved on $9^{\text {th }}$ April 2021 from:

https://help.surveymonkey.com/articles/en US/kb/What-settings-allowmultiple-responses-from-one-computer

Taber, K.S. (2018). The Use of Cronbach's Alpha When Developing and Reporting Research Instruments in Science Education. Research in Science Education, 48: 1273-1296. DOI: 10.1007/s11165-016-9602-2.

Usability.gov. (undated). Online Surveys. Retrieved on $10^{\text {th }}$ June 2021 from: https://www.usability.gov/how-to-and-tools/methods/online-surveys.html

Warugaba, C., Naughton, B., Gauthier, B.H., Muhirwa, E., \& Amoroso, C.L. (2016). Experience with a Massive Open Online Course in Rural Rwanda. The International Review of Research in Open and Distributed Learning, 17(2): 222-231. DOI: 10.19173/irrodl.v17i2.2401.

Wright, K.B. (2005). Researching Internet-Based Populations: Advantages and Disadvantages of Online Survey Research, Online Questionnaire Authoring Software Packages, and Web Survey Services. Journal of ComputerMediated Communication 10(3): JCMC1034. DOI: 10.1111/j.10836101.2005.tb00259.x 
Zekiwos-Gichamo, T., Karltum, E., Tolera, M., Chiwona-Karltum, L. (2019). The Impact of Faba Bean Theft in Rural Ethiopia: To Dispute or to Reside

790 Together in Harmony? International Journal of Rural Criminology, 4(2): 217-

791 239.

792 